\title{
On the thermo-electric spark, as obtained from a single pair of metallic elements
}

\section{Mr. Francis Watkins}

To cite this article: Mr. Francis Watkins (1837) On the thermo-electric spark, as obtained from a single pair of metallic elements, Philosophical Magazine Series 3, 11:68, 398-399, DOI: 10.1080/14786443708649304

To link to this article: http://dx.doi.org/10.1080/14786443708649304

册 Published online: 01 Jun 2009.

Submit your article to this journal $\sqsubset \pi$

Џ Article views: 2

Q View related articles $\widetilde{ }$ 
vitriol or the sulphate of water absorbs the same proportion of am. monia, the bisulphate of ammonia being produced. The two products are of the same constitution. The basic adjunct, ammonia, is attached to oxide of copper in the one case, and to oxide of hydrogen in the other. Both are double salts, and may be expressed by the following formulæ:-

$$
\begin{gathered}
\mathrm{Cu} \ddot{\mathrm{S}}+\mathrm{NH}^{3} \mathrm{Cu} \dddot{\mathrm{S}} \text {, and } \\
\dot{\mathrm{H}} \dddot{\mathrm{S}}+\mathrm{NH}^{3} \dot{\mathrm{H}} \dddot{\mathrm{S}} \text {. }
\end{gathered}
$$

It thus appears that the ordinary ammoniacal salts which contain water, are a particular class of an extensive order of salts; as, for the water there may be substituted oxide of copper, oxide of zinc, nickel, cobalt, and many others. Many of these combinations are capable of assuming an additional dose of ammonia, which, however, is feebly retained, and is in a relation to the salt like that of water of crystallization.

In the discussion which took place on Prof. Gralıam's communication, Mr. Richard Phillips gave it as his opinion, that the difference between constitutional water and basic water arises from the wellknown law, that when one principle combines with more proportions than one of another, the first proportion is held with a stronger affinity than the others. - Mr. G. Bird could not conceive how water could be considered as a base, and inquired what view Professor Graham would take of the function of the atom of water in oil of vitriol and in caustic potash.-Dr. Faraday expressed his satisfaction that such a variety of opinions should be advanced, and even be maintainable by powerful arguments, upon so interesting a subject ; for, from this collision of opinion, it was most likely that the truth would ultimately be struck out. He also cautioned chemists against considering electrical relations as affording, in every instance, conclusive proofs of what is a base and what is an acid.-Prof. Johnston concurred in the observation of Dr. Faraday, and professed that he had a very strong leaning to the theoretical views in reference to the constitution of salts which had been just propounded by Professor Graham.-Dr. Kane made some remarks on the same subject, objecting to some of Professor Graham's statements. To these Professor Graham briefly replied, and the discussion closed.Athencum, Sept. 23, p. 695.

\section{Intelligence and Miscellaneous Articles.}

ON THE THEKMO-ELECTRIC SPARK, AS OBTAINED FROM A SINGLE PAIR OF METALLIC EIFMEN'IS. BY MR. FRANCIS. WATKINS.

To the Editors of the Philosophical Magazine and Journal.

\section{GentLemen,}

THOPE you will allow me to make known in your forthcoming publication a fact in thermo-electricity which I have observed since my last comnunication to you, and which 1 believe has not been noticed in print in this or any other country. 
With a pair of metallic elements, consisting of one bismuth and one antimony, weighing each tive grains and measuring 0.5 of an inch long and 0.12 diameter, when their extremities were unequally heated, I have obtained, with a Henry's flat ribbon coil, a very perceptible and brilliant spark.

I have had the pleasure of showing the experiment to MM. De la Rive, Plateau, and Netschayef, and I need not add that these distinguished philosophers were much delighted on seeing the ther$m o$-electrical light developed by a single pair of metallic elements.

Now I have pen in hand permit me to state that with thermo-piles I actuate most of the apparatus usually employed for illustrating electro-magnetic phænomena, so that the public teacher may now show by the same apparatus the several rotations, \&c. with thermoelectricity, as he does with voltaic electricity.

5, Charing Cross.

I remain, Gentlemen, \&c.

Francis Watkins.

ON THE ARTIFICIAL PREPARATION OF FORMIC ACID.

Prof. J. B. Emmet of the University of Virginia makes the following observations respecting, and proposes the annexed methods of preparing formic acid :

One part of tartaric acid (or sugar), one and a half of peroxide of manganese, one and a half of sulphuric acid, diluted with about two and a half parts of water, when well mixed and subjected to distillation, will furnish the formic acid according to Dobereiner's process. In order to diminish the inconvenience arising from the frothing of this mixture, and which is exceedingly great, it is directed to add only half the amount of dilute acid at first, and to make use of a retort having five or six times the bulk of the matter to be put into it.

The explanation given by Dobereiner and other chemists, assigns to the peroxide of manganese an agency absolutely necessary for success, viz. that, while it parts with a portion of its own oxygen and combines, as the protoxide, with sulphuric acid, it is enabled by the oxygen thus detached, to convert the tartaric acid (or sugar) into the formic and carbonic acids.

The whole of this explanation is, however, incorrect, as will appear from the following results of my inquiry.

1. The presence of peroxide of manganese, (or any other peroxide, ) is not only unnecessary, but positively injurious and productive of much inconvenience. It is positively injurious in cunsequence of the power which all peroxides bave of decomposing formic acid, and productive of inconvenience in consequence of the vast amount of carbonic acid which it produces with the formic acid and the carbon deposited during the operation. The latter is, in fact, the cause of the excessive frothing.

2. Sulphuric acid is not essential. The formic acid was prepared by phosphoric acid as well as by the chloride of tin; and no doubt all other substances, capable of converting alcohol into æather, may be shown to possess the same power. In no case does sulphuric acid, 